(C) American Psychological Association, 2019. This paper is not the copy of record and may not exactly replicate the authoritative document published in the APA journal. Please do not copy or cite without author's permission. The final article is available at: $: 10.1037 /$ ser0000352

\title{
Advocacy for improved response to self-injury in schools: A call to action for school
} psychologists.

\section{Abstract}

Over the past several years, nonsuicidal self-injury (NSSI) has emerged as a widespread concern in school settings worldwide. However, despite significant strides in NSSI research, there remains a substantial knowledge gap with respect to what school staff know.

Unfortunately, this can contribute to stigma and ineffective responding when working with students who self-injure. In light of its high rates and the risks with which NSSI associates, including death by suicide, this is worrisome. Accordingly, there is a pressing need for advocacy in schools to ensure that NSSI is prioritized and for proper knowledge and training be offered to school staff. The current article serves as a call to action for school psychologists as leaders and advocates in meeting these needs. We begin by articulating the central issues pertinent to low NSSI literacy and high NSSI stigma in schools, followed by a series of research-informed recommendations for timely and effective advocacy. By virtue of undertaking these initiatives, school staff will be better able to respond to the needs of youth who self-injure and advocate for them. This, in turn, can foster an enhanced school climate and greater student well-being. (PsycInfo Database Record (c) 2020 APA, all rights reserved)

Defined as the purposeful and immediate damage (e.g., cutting, burning) of one's own bodily tissue without intent to die by suicide, nonsuicidal self-injury (NSSI) represents a highly prevalent and paramount concern in school settings across the globe (see Hasking et al., 2016). Indeed, up to one in five youth report having self-injured, and those who engage in NSSI report more mental health difficulties (e.g., depression, trouble managing painful emotions, anxiety, 
(C) American Psychological Association, 2019. This paper is not the copy of record and may not exactly replicate the authoritative document published in the APA journal. Please do not copy or cite without author's permission. The final article is available at: :10.1037/ser0000352

eating disorders) than those who do not self-injure(for a review, see Lewis \& Heath, 2015).

Young people who self-injure also experience more interpersonal difficulties such as bullying, lower school connectedness, and poorer academic performance (Dobry, Braquehais, \& Sher, 2013; Garisch \& Wilson,2015;Martin, Richardson, Bergen, Roeger, \& Allison, 2005;Ro-tolone \& Martin, 2012). Of grave concern are findings indicating that NSSI represents a significant suicide risk factor (for a review, see Hamza, Stewart, \& Willoughby, 2012). Yet NSSI knowledge is generally low across school stakeholders, and NSSI remains shrouded in stigma within school contexts, contributing to poor responses to students (e.g., ineffective responses during initial discussions or in the context of assessment and intervention, poorly timed responses; see De Riggi, Moumne, Heath, \& Lewis,2017; Hasking et al., 2016). Hence, there is a pressing need for advocacy in schools when addressing NSSI.

With this in mind, we, the International Consortium on Self-Injury in Educational Settings (ICSES), present the current call-for-action paper for school psychologists, who, in their role as advocates in schools, can champion for a better overall response(both timely and effective) to students who engage in NSSI. ICSES comprises established researchers and clinicians (including ones who work in school settings) from around the globe who are well regarded for their work on NSSI. ICSES brings this collective expertise to focus on understanding and responding to NSSI in educational contexts. In the current article, we seek to provide psychologists in schools with the necessary information, resources, and concrete steps to effectively advocate for students who engage in NSSI, so that schools and all school personnel can recognize the centrality of addressing NSSI and how this can be accomplished Specifically, the aims of the current article are to (a) highlight key issues related to NSSI knowledge and 
(C) American Psychological Association, 2019. This paper is not the copy of record and may not exactly replicate the authoritative document published in the APA journal. Please do not copy or cite without author's permission. The final article is available at: :10.1037/ser0000352

stigma within schools, and(b) provide research-informed recommendations outlining essential steps for effective NSSI advocacy in school settings.

\section{Prioritizing NSSI Advocacy}

Although there are many concerns warranting advocacy within schools, NSSI should be viewed as an especially critical issue. A recent and growing line of evidence indicates that NSSI is both a robust and unique factor contributing to suicide risk (for reviews, see Franklin \& Nock, 2016; Hamza et al., 2012), even when controlling for other factors known to confer suicide risk (e.g., depressive symptoms; e.g., Klonsky, May, \& Glenn, 2013). Further, in keeping with the high rates of NSSI among school-aged youth, there are numerous reports of clusters of youth who self-injure within different school contexts (e.g., individual classes, grade levels, peer groups; see, e.g., Prinstein et al., 2010; Walsh \& Muehlenkamp, 2013; You, Lin, Fu, \& Leung, 2013); in some cases, this may involve youth self-injuring at school. Although there are multiple psychosocial processes contributing to these occurrences, this phenomenon is typically referred to as social contagion of NSSI (see Jarvi, Jackson, Swenson, \& Crawford, 2013). Despite the ubiquity with which the term contagion is attached to NSSI, given the inherent link between contagion and disease, this can evoke unhelpful attitudes and stigma, which, in turn, can contribute to isolation among students who self-injure (e.g., Hasking \& Boyes, 2018). Accordingly, reports of NSSI occurring among groups of youth merit attention, as schools are often left in the dark with respect to how to address NSSI when these clusters emerge. Position papers to address NSSI in schools (including the NSSI occurring in groups) may thus be of interest to readers wishing for additional information (see De Riggi et al., 2017; Hasking et al., 2016). As discussed later, this issue is just one of many NSSI-related concerns for which schools 
(C) American Psychological Association, 2019. This paper is not the copy of record and may not exactly replicate the authoritative document published in the APA journal. Please do not copy or cite without author's permission. The final article is available at: $: 10.1037 /$ ser0000352

feel ill-equipped. Considering the myriad risks with which NSSI associates (see Hasking et al., 2016; Lewis \& Heath, 2015), this is worrisome.

\section{Knowledge-Practice Gap}

In response to recognition that NSSI is associated with poorer academic performance, worsening mental health, and potentially suicidal thoughts and behaviors, research on NSSI has increased dramatically over the past decade (see Lewis \& Heath, 2015; Martin et al., 2005; Whitlock et al., 2013). As a result, there have been major advances in the field, yet these are only just beginning to be translated into practice in the school context (e.g., De Riggi et al., 2017).

This knowledge-practice gap means that despite a significant body of research to draw on, school staff (e.g., teachers, administrators, and in some cases mental health professionals) remain undereducated regarding the nature and extent of NSSI and the most appropriate ways to respond to students who self-injure. This lack of knowledge, and associated lack of confidence in addressing NSSI, can lead to inappropriate responses to disclosures (e.g., over- or underreaction) and inadequate referral, follow-up, and intervention (Heath, Toste, Sornberger, \& Wagner, 2011). As a result, students may be left feeling misunderstood and further stigmatized, limiting future help seeking and increasing risk of subsequent NSSI (De Riggi, et al., 2017; Heath et al., 2011; Toste \& Heath, 2010). We argue that school psychologists have a role to play, both in advocating for professional development for all staff and in ensuring the latest research findings are implemented into practice. In doing so, school psychologists can have an impact not only on individual students but also on a school and systems level (e.g., school boards, education departments). 
(C) American Psychological Association, 2019. This paper is not the copy of record and may not exactly replicate the authoritative document published in the APA journal. Please do not copy or cite without author's permission. The final article is available at: $: 10.1037 /$ ser0000352

Although most school staff (including educators, school mental health practitioners, and administrators) have encountered a student who engages in NSSI, as many as $80 \%$ report never having received any training or education on NSSI (Berger, Hasking, \& Reupert, 2014; Berger, Reupert, \& Hasking, 2015; Carlson, DeGeer, Duer, \& Fenton, 2005; Duggan, Heath, Toste, \& Ross, 2011; Heath, Toste, \& Beettam, 2006). Commensurate with this, the vast majority of school staff report having only a superficial knowledge about NSSI and feel ill-equipped to respond to, and support, students who self- injure (Berger et al., 2014, 2015; Carlson et al., 2005; Duggan et al., 2011; Heath et al., 2006, 2011; Kelada, Hasking, \& Melvin, 2017; Roberts-Dobie \& Donatelle, 2007). However, translation of knowledge about NSSI to school staff has improved over the last few decades. For example, many school staff can identify the age at which NSSI typically has its onset (i.e., early to mid- adolescence), as well as common methods of NSSI (e.g., cutting, burning), and have improved their understanding of NSSI as an emotion regulatory, rather than manipulative, behavior (Berger et al., 2014, 2015; Best, 2005, 2006; Carlson et al., 2005; Heath et al., 2006, 2011). There is some evidence that both early-career educators and staff with experience working with students who self- injure demonstrate greater knowledge and confidence in responding to students who self-injure (Berger et al., 2014, 2015; Heath et al., 2011). This might suggest that more recent training in college and universities and on-the-job experience are both helpful in facilitating responses to students who self-injure. In line with these findings, mental health practitioners report higher levels of knowledge relative to other school staff (e.g., educators, administrators). Yet despite advances in knowledge translation, staff still underestimate how prevalent NSSI is among school-aged youth, and most school psychologists (and other school mental health professionals) still report they are lacking in knowledge, have low confidence in addressing NSSI, and that greater training on NSSI is 
(C) American Psychological Association, 2019. This paper is not the copy of record and may not exactly replicate the authoritative document published in the APA journal. Please do not copy or cite without author's permission. The final article is available at: :10.1037/ser0000352

necessary (Berger et al., 2014; De Stefano, Atkins, Noble, \& Heath, 2012; Roberts-Dobie \& Donatelle, 2007).

Findings to date highlight the value of increasing NSSI literacy in schools. School staff who have knowledge of NSSI tend to have more positive attitudes toward NSSI and are more confident in their abilities to identify and respond to NSSI appropriately (Berger et al., 2015). Moreover, training efforts aimed at equipping school staff with information about NSSI have been shown to increase knowledge about NSSI, increase confidence in responding to NSSI, and produce self-reported behavioral changes in NSSI responding (Groschwitz, Munz, Straub, Bohnacker, \& Plener, 2017). Notably, in one study, these knowledge gains were maintained after 6 months (Groschwitz et al., 2017). Because NSSI is often hidden and concealed (Armiento, Hamza, \& Willoughby, 2015; Hasking, Rees, Martin, \& Quigley, 2015; Nixon, Cloutier, \& Jansson, 2008), understanding the co-occurrence of NSSI and other mental health concerns (i.e., improving general mental health literacy) may also help facilitate identification of youth who self- injure (Askell-Williams \& Lawson, 2013; De Riggi et al., 2017; Jorm, Kitchener, Sawyer, Scales, \& Cvetkovski, 2010; Kutcher, Wei, McLuckie, \& Bullock, 2013; Schatten, Morris, Wren, \& Andover, 2013). Most importantly, a school-wide NSSI response protocol and schoolboard policy with clearly articulated roles for all staff is essential (De Riggi et al., 2017; Hasking et al., 2016). As discussed further later, higher NSSI knowledge is conducive to a better overall response to NSSI in schools and to combatting NSSI stigma.

We appreciate that ensuring that school staff have appropriate training in NSSI is challenging for schools. School staff are al- ready charged with not only educating young people but also addressing social issues such as racism and bullying, health issues such as drug use and safe sex practices, and mental health concerns such as depression and anxiety. The culture of a 
(C) American Psychological Association, 2019. This paper is not the copy of record and may not exactly replicate the authoritative document published in the APA journal. Please do not copy or cite without author's permission. The final article is available at: :10.1037/ser0000352

school (i.e., academic vs. well-being focused) can play a large role in whether school staff receive training regarding how best to respond to and address NSSI. Particularly in elementary schools, the focus may be on behavior management and psychoeducational assessments rather than on fostering emotional development among students. A shortage of school psychologists in schools can also determine where resources are allocated when it comes to education and training about mental health issues. The decision to prioritize professional development for NSSI typically occurs at the administrative and systems level. Unfortunately, schools are caught in a Catch-22: School administrators will only invest in training if NSSI is viewed as a priority, but accurate knowledge about NSSI is required to establish NSSI as a priority. We call on school psychologists to be advocates for evidence-based practice, increasing knowledge of NSSI and familiarization with the implementation of school protocols at all levels within the school.

\section{Challenge of Stigma}

Related to the aforementioned knowledge gaps regarding NSSI among school professionals, NSSI remains marred by significant stigma, which can, unfortunately, translate to unhelpful attitudes toward students who self-injure (e.g., De Riggi et al., 2017; Hasking et al., 2016; Muehlenkamp, Walsh, \& McDade, 2010). Al- though this is perhaps unsurprising given the rampant stigma associated with NSSI in the general public (e.g., Lewis \& Heath, 2013; Lewis, Mahdy, Michal, \& Arbuthnott, 2014), it underscores the need for greater advocacy to address such stigma within schools. As discussed earlier, poor responses to NSSI, which may, in part, stem from stigma, can have detrimental effects on youth who self-injure (see Hasking et al., 2016). 
(C) American Psychological Association, 2019. This paper is not the copy of record and may not exactly replicate the authoritative document published in the APA journal. Please do not copy or cite without author's permission. The final article is available at: $: 10.1037 /$ ser0000352

Stigma associated with NSSI and young people who self-injure can impede the manner by which NSSI is understood (and ultimately addressed) in school settings. If NSSI and students who self-injure are viewed negatively, NSSI may be dismissed or conversations with students about NSSI may transpire in ways that invalidate the experience of said students. Poor responses to youth who self-injure may exacerbate students' feelings of isolation and their reluctance to reach out to others for support—especially because students who self-injure already feel disconnected and misunderstood (e.g., De Riggi et al., 2017; Hasking et al., 2016; Lewis \& Heath, 2015; Muehlenkamp et al., 2010). Thus, approaches to address NSSI in schools, including implementation of school-wide protocols and training related to NSSI for school staff, should spend time focusing on issues related to stigma —including stigma toward NSSI from others as well as self-directed stigma among those students who self-injure. With increased knowledge of the impact of stigma as it pertains to NSSI, alongside increased NSSI literacy and confidence when working with students who self-injure (discussed earlier), school psychologists and other school mental health professionals will be in a better position to prioritize and advocate for improved responses to NSSI within school contexts.

Schools can assist in reducing stigma by assuring that responses to NSSI among staff are calm and compassionate, that students are not shamed or blamed, and that the students' physical and emotional needs are met with caring and direct attention. Ideally, all communication with youth about the behavior (verbal and nonverbal) convey respect, a willingness to understand, and attentiveness to the student's needs and well-being. Because NSSI is often accompanied by low self-esteem and fear of rejection (e.g., Brausch \& Gutierrez, 2010; Martin et al., 2005), it is vital to avoid inadvertently reinforcing these negative associations, particularly because responses to first disclosures that are perceived to be harsh or judgmental can reduce the likelihood of future 
(C) American Psychological Association, 2019. This paper is not the copy of record and may not exactly replicate the authoritative document published in the APA journal. Please do not copy or cite without author's permission. The final article is available at: :10.1037/ser0000352

disclosures and thus delay needed support and/or treatment (Rosenrot \& Lewis, 2018; Walsh, 2012). Moreover, implicitly or explicitly communicating judgment or disgust can exacerbate internalized stigma, thwart help seeking, and thus reinforce the behavior. Instead, schools have an important role to play in encouraging youth who self-injure to accept and/or seek support in and out of school. School professionals who work with students who engage in NSSI can validate youth fears and concerns about disclosing to others, such as parents or therapists, while simultaneously assisting them in broadening their support system.

\section{ICSES Recommendations for Effective Advocacy}

As a group of international leaders who conduct research in the field and engage in outreach to educate about NSSI, while working together with those with lived NSSI experience, we provide the following recommendations for effective advocacy by school psychologists and other school mental health professionals; these are summarized in Figure 1. These recommendations are built on research-informed guidelines (De Riggi et al., 2017; Hasking et al., 2016) as well as by our own NSSI advocacy activities in individual schools and school systems. Recommendations are also offered with the recognition that school psychologists (and related school mental health professionals) are likely tasked with multiple roles in their school (and, at times, multiple schools). Indeed, the recommendations articulated later should be used with consideration to potential limitations in time, resources, and other factors (e.g., advocacy may be at odds with administrative priorities), which are bound to vary across schools and school districts. Accordingly, we highlight the importance of ensuring that all school professionals are involved in addressing NSSI and offer suggestions to involve others including external resources if needed; when appropriate, we indicate how school psychologists can realistically engage in advocacy given their many demands. 
(C) American Psychological Association, 2019. This paper is not the copy of record and may not exactly replicate the authoritative document published in the APA journal. Please do not copy or cite without author's permission. The final article is available at: $: 10.1037 /$ ser0000352

\section{Preparation for Advocacy and Ensuring NSSI Literacy}

The very first step in effective advocacy is informing oneself about NSSI and effective response. Although psychologists and other mental health professionals in the school may have some knowledge and understanding of NSSI, not all have received training or professional development in the area. Seeking out relevant information is essential in order to position oneself for advocacy. We have provided helpful resources for mental health professionals in schools to ensure they have the necessary knowledge to serve in their advocacy role (see Figure 2). Furthermore, the research and knowledge in the area of NSSI among youth continues to grow and evolve, with annual increases in the number of articles published with keywords such as selfinjury and self- harm (Web of Science, 2018; www.webofknowledge.com ). Thus, in order to maintain current knowledge in the area, school mental health professionals need to actively engage in ongoing professional development in the field. This can be done through monitoring of recommended websites (see Figure 2), which will provide updates to new research and school applications and are publicly accessible.

\section{Engage With School Decision Makers to Persuade Prioritization}

Upon obtaining the requisite knowledge regarding NSSI, the next step in advocating for effective support of students who self-injure is to employ that information in an effort to persuade administrators (at the school or system level depending on one's role) to prioritize NSSI professional development. This not only ensures that NSSI is effectively addressed but that all school professionals are involved. Given the multifaceted role that school psychologists (and other mental health professionals) play in schools, this is essential. Moreover, we are cognizant 
(C) American Psychological Association, 2019. This paper is not the copy of record and may not exactly replicate the authoritative document published in the APA journal. Please do not copy or cite without author's permission. The final article is available at: $: 10.1037 /$ ser0000352

that in some areas, there may be one school psychologist associated with several schools. Thus, involvement of others (e.g., school nurses, social workers) would be critical.

Drawing on our earlier discussion, essential points to be shared in efforts to upskill administrators include (a) the prevalence of NSSI, highlighting that although it is frequently hidden, it is very prevalent and is indeed occurring in your school(s); (b) emphasizing that it is not about attention seeking or manipulation, is not a fad, and, although distinct from suicide, it is a serious mental health concern associated with numerous deleterious outcomes, including significant increased risk for suicide; (c) the likelihood of students speaking among themselves about this behavior leading to further difficulties and possible unexpected challenges (including parental concerns) if the school is not already addressing the behavior; and (d) the costs of not addressing NSSI effectively. It is the authors' experience that administrators' hesitancy to prioritize addressing NSSI in the schools often arises from misconceptions concerning the behavior and its impact on youth as well as competing demands (e.g., implementation of curriculum). Therefore, beyond addressing these critical knowledge domains, school psychologists can highlight the impact of not addressing NSSI. In this regard, it can be communicated that many students who engage in NSSI are apt to miss time in school, thus increasing their total days of absenteeism. Furthermore, school performance can be adversely affected by NSSI (Kiekens et al., 2016; Martin et al., 2005). These additional reasons may further persuade school administrators (and other decision makers) to view NSSI as mer- iting prioritization.

\section{Closing the Research-Practice Gap and Challenging Stigma via Knowledge Mobilization}


(C) American Psychological Association, 2019. This paper is not the copy of record and may not exactly replicate the authoritative document published in the APA journal. Please do not copy or cite without author's permission. The final article is available at: $: 10.1037 /$ ser0000352

Once administrative support has been obtained, the next step is to increase awareness and NSSI knowledge while challenging stigma in order to lay the groundwork for developing a policy for effective response; we outline the key parts of a school-based protocol (i.e., response) for NSSI in Step 3 of Figure 1. In what follows, we have outlined the specific needs of the different school personnel and associated approaches for working with them.

Administrators. As indicated earlier, administrators need initial persuasion for the need to address NSSI and the relevance to the school(s). Administrators would have already been provided with much of the basic information regarding NSSI (noted earlier) by this point. However, school psychologists (or other school mental health professionals) should subsequently work to help administrators see the benefit of their school(s) being progressive and conducting NSSI school-wide training. This can involve bringing together other school mental health professionals who work with and support youth in schools to share in developing and delivering a potent and unified message that describes NSSI within the context of enhancing and supporting the mental health and well-being of all students. Specifically, these discussions should highlight various forms of healthy and unhealthy coping, wherein NSSI is contextualized as just one of many unhealthy coping behaviors; in this way, the overall focus of the conversation is on fostering healthier coping versus NSSI in particular. Administrators need to be made aware of the overarching plan for addressing NSSI (described later) and consulted with and involved as needed across each step. By having multiple professionals involved in this process, these subsequent updates and consultations can be shared, thereby reducing the workload of approaching this individually. For cases in which there is a single school psychologist across several schools, it may be useful to identify point people at individual schools to undertake some of these tasks. 
(C) American Psychological Association, 2019. This paper is not the copy of record and may not exactly replicate the authoritative document published in the APA journal. Please do not copy or cite without author's permission. The final article is available at: $: 10.1037 /$ ser0000352

School staff, mental health professionals, and administration together. Next, it is recommended that a school-wide professional development workshop occur, addressing what NSSI is and is not, challenging common misconceptions, how best to respond to NSSI, and sharing appropriate materials and information (see Figure 1). This could be facilitated by school psychologists and/or other school mental health professionals. However, this may not always be feasible given the multiple roles that these individuals play in the school and school board. Thus, training opportunities and workshops may necessitate involvement of outside support (e.g., expert researchers and clinicians in the NSSI field who are brought into the school). Similarly, coordinating with nearby schools to offer shared training may represent another viable strategy.

Ultimately, it is important to ensure that all new staff, school mental health professionals, and administrators receive this information when they join the school. This can be accomplished by having materials available for sharing and holding a small "new personnel orientation" at the start of each school year to ensure that everyone has the same information; alternatively, this can occur if schools review their response to NSSI on a regular (e.g., annual) basis. Involving various professionals in the role of resource pro- vision and offering brief orientations may be warranted; indeed, this may help to increase others' involvement, which ensures that all school professionals feel invested in addressing NSSI. Partner- ing with external community resources may also be needed in order to ensure that youth who require outside or longer term support are appropriately referred and supported.

In addition to the initial professional development workshop and the new personnel orientation, there should be a yearly review of the effective response to NSSI procedure. This yearly review can be led within a team context and can help determine whether anything has changed, address any unexpected challenges (while being sure to respect confidentiality), share 
(C) American Psychological Association, 2019. This paper is not the copy of record and may not exactly replicate the authoritative document published in the APA journal. Please do not copy or cite without author's permission. The final article is available at: $: 10.1037 /$ ser0000352

successes, and remind and recommit staff to effective NSSI response. Once the school policy on NSSI (see Step 4 in Figure 1) is developed, this should be shared with new personnel and updated at the review (see Step 5 in Figure 1).

Students. Once the school personnel have completed their professional development, it is important to work with students themselves. Our recommendation is that the school psychologists (or other school mental health professionals, depending on the setting and what is available) conduct a school-wide session with students, focusing on improving healthy coping; in the case of larger schools, multiple sessions may be required for pragmatic reasons. Reviewing an array of both healthy and unhealthy coping behaviors and situating NSSI as just an example of an unhealthy coping behavior, not dissimilar to substance use to self-medicate, decreases stigma and avoids sensationalizing the behavior. The session can explore a wide range of healthy and unhealthy coping behaviors, provide more information and materials about these unhealthy coping behaviors, and offer suggestions for students on how they can respond to friends (and other fellow students) who are engaging in these behaviors. Subsequently, it is important to provide resources to help students further develop healthy coping. Ending the session with information on help seeking within the schools, outlining the mental health professionals that students can turn to and relevant resources, is beneficial.

Parents and families. Recruiting parents for information ses- sions on healthy and unhealthy coping in parallel with the student sessions, albeit in a distinct session, is ideal but rarely feasible. However, the provision of parent information sheets on the topic to be sent to parents at the same time as informing them of the student session can be helpful. Including suggested materials and re- sources on the most common unhealthy behaviors as well as information on healthy alternatives is recommended. Providing a contact number at the school in 
(C) American Psychological Association, 2019. This paper is not the copy of record and may not exactly replicate the authoritative document published in the APA journal. Please do not copy or cite without author's permission. The final article is available at: :10.1037/ser0000352

the event that the student has questions or concerns (about the information or the session) is also advisable. In addition, school psychologists should have a list of NSSI resources specifically for parents, as well as hard copies (see Figure 2), available to be shared with parents or families at short notice as needed.

\section{Ensuring Effective Response}

In addition to advocating to prioritize NSSI and providing training to challenge stigma, school psychologists (or other mental health professional within a school context) are in an optimal position to advocate for and ensure effective response. An essential element in ensuring effective response to NSSI within schools is the development, distribution, monitoring, and evaluation of a school policy or protocol (see De Riggi et al., 2017; Hasking et al., 2016). The NSSI school protocol is distinct from a suicide proto- col, as the response is different. Once the protocol is developed (following guidelines described in Step 3 of Figure 1), it is important to share it through professional development activities, new staff orientations, and yearly reviews (see Steps 6 and 7 of Figure 1). Posting the protocol in the staff room and in the administrators' and school psychologists' offices can also keep staff aware of it. Furthermore, ongoing monitoring of protocol use can help identify potential problems that require revision (Step 6 of Figure 1). A formal review and evaluation should be planned yearly to determine the overall use of the protocol and status of effective NSSI response. Finally, in one's advocacy role, sharing one's own experience with effective NSSI response with other schools in one's district or system will further contribute to improved school response to NSSI.

\section{Conclusion}


(C) American Psychological Association, 2019. This paper is not the copy of record and may not exactly replicate the authoritative document published in the APA journal. Please do not copy or cite without author's permission. The final article is available at: $: 10.1037 /$ ser0000352

Almost one in five school-based adolescents have self-injured at some point - that is approximately five students in every class- room (Muehlenkamp, Claes, Havertape, \& Plener, 2012; Swannell, Martin, Page, Hasking, \& St John, 2014). Given associations with poor academic performance, limited school connectedness, poor mental health, and subsequent suicidal thoughts and behaviors, NSSI is a behavior that demands to be taken seriously by schools and by school psychologists. Clearly distinct from suicidal thoughts and behaviors, NSSI must be addressed in its own right, with clear protocols and procedures for addressing and responding to NSSI in schools.

School psychologists are in a prime position to advocate for NSSI to be prioritized in schools, to campaign for staff training, to actively work against stigma, and to support students who self- injure. Effective advocacy can result in real changes in how people who self-injure are perceived and addressed in the school setting (Groschwitz et al., 2017), which can have a significant effect on the self-respect, confidence, and well-being of young people. Ac- curate knowledge and supportive attitudes among school staff can make a tremendous difference in the lives of students who self- injure, their peers, and their families (Berger et al., 2014). In this article, we call for all school psychologists to take up the mantle and be proactive advocates for young people who self-injure, to demand that NSSI is prioritized as a substantive issue within schools, and to ensure that all young people who self-injure are treated with the respect and care they deserve. 
(C) American Psychological Association, 2019. This paper is not the copy of record and may not exactly replicate the authoritative document published in the APA journal. Please do not copy or cite without author's permission. The final article is available at: :10.1037/ser0000352

\section{References}

Armiento, J. A., Hamza, C. A., \& Willoughby, T. (2015). An examination of disclosure of nonsuicidal self-injury among university students. Jour- nal of Community \& Applied Social Psychology, 24, 518 -533. http://dx.doi.org/10.1002/casp.2190

Askell-Williams, H., \& Lawson, M. J. (2013). Teachers' knowledge and confidence for promoting positive mental health in primary school communities. Asia-Pacific Journal of Teacher Education, 41, 126 -143. http://dx.doi.org/10.1080/1359866X.2013.777023

Berger, E., Hasking, P. A., \& Reupert, A. (2014). "We're working in the dark here": Education 
(C) American Psychological Association, 2019. This paper is not the copy of record and may not exactly replicate the authoritative document published in the APA journal. Please do not copy or cite without author's permission. The final article is available at: $: 10.1037 /$ ser0000352

needs of teachers and school staff regarding student self-injury. School Mental Health: A Multidisciplinary Research and Practice Journal, 6, 201-212. http://dx.doi.org/10.1007/s12310013-9114-4

Berger, E., Reupert, A., \& Hasking, P. A. (2015). Pre-service and in- service teachers' knowledge, attitudes and confidence towards self- injury among pupils. Journal of Education for Teaching, 41, 37-51. http://dx.doi.org/10.1080/02607476.2014.992633

Best, R. (2005). An educational response to deliberate self-harm: Training support and schoolagency links. Journal of Social Work Practice, 19, 275-287. http://dx.doi.org/10.1080/02650530500291070

Best, R. (2006). Deliberate self-harm in adolescence: A challenge for schools. British Journal of Guidance \& Counselling, 34, 161-175. http://dx.doi.org/10.1080/03069880600583196

Brausch, A. M., \& Gutierrez, P. M. (2010). Differences in non-suicidal self-injury and suicide attempts in adolescents. Journal of Youth and Adolescence, 39, 233-242. http://dx.doi.org/10.1007/s10964-009-9482-0

Carlson, L., DeGeer, S. M., Duer, C., \& Fenton, K. (2005). Teacher's awareness of self-cutting behavior among adolescent population. Praxis, 5, 22-29.

De Riggi, M. E., Moumne, S., Heath, N. L., \& Lewis, S. P. (2017). Non-suicidal self-injury in our schools: A review and research-informed guidelines for school mental health professionals. Canadian Journal of School Psychology, 32, 122-143. http://dx.doi.org/10.1177/0829573516645563 
(C) American Psychological Association, 2019. This paper is not the copy of record and may not exactly replicate the authoritative document published in the APA journal. Please do not copy or cite without author's permission. The final article is available at: $: 10.1037 /$ ser0000352

De Stefano, J., Atkins, S., Noble, R. N., \& Heath, N. (2012). Am I competent enough to be doing

this? A qualitative study of trainees' experiences working with clients who self-injure.

Counselling Psychol- ogy Quarterly, 25, 289 -305.

http://dx.doi.org/10.1080/09515070.2012.698981

Dobry, Y., Braquehais, M. D., \& Sher, L. (2013). Bullying, psychiatric pathology and suicidal

behavior. International Journal of Adolescent Medicine and Health, 25, 295-299. http://dx.doi.org/10.1515/ijamh-2013-0065

Duggan, J. M., Heath, N. L., Toste, J. R., \& Ross, S. (2011). School counsellors' understanding of nonsuicidal self-injury: Experiences and international variability. Canadian Journal of Counselling and Psycho- therapy, 45, 327-348.

Franklin, J. C., \& Nock, M. K. (2016). Nonsuicidal self-injury and its relation to suicidal behavior. In P. M. Kleespies (Ed.), The Oxford handbook of behavioral emergencies and crises (pp. 401-416). New York, NY: Oxford University Press.

Garisch, J. A., \& Wilson, M. S. (2015). Prevalence, correlates, and pro- spective predictors of non-suicidal self-injury among New Zealand adolescents: Cross-sectional and longitudinal survey data. Child and Adolescent Psychiatry and Mental Health, 9, 28. http://dx.doi.org/10 .1186/s13034-015-0055-6

Groschwitz, R., Munz, L., Straub, J., Bohnacker, I., \& Plener, P. L. (2017). Strong schools against suicidality and self-injury: Evaluation of a work- shop for school staff. School Psychology Quarterly, 32, 188 -198. http:// dx.doi.org/10.1037/spq0000185 
(C) American Psychological Association, 2019. This paper is not the copy of record and may not exactly replicate the authoritative document published in the APA journal. Please do not copy or cite without author's permission. The final article is available at: $: 10.1037 /$ ser0000352

Hamza, C. A., Stewart, S. L., \& Willoughby, T. (2012). Examining the link between nonsuicidal self-injury and suicidal behavior: A review of the literature and an integrated model. Clinical Psychology Review, 32, 482-495. http://dx.doi.org/10.1016/j.cpr.2012.05.003

Hasking, P., \& Boyes, M. (2018). Cutting words: A commentary on language and stigma in the context of nonsuicidal self-injury. Journal of Nervous and Mental Disease, 206, 829 833. http://dx.doi.org/10.1097/ NMD.0000000000000899

Hasking, P. A., Heath, N. L., Kaess, M., Lewis, S. P., Plener, P. L., Walsh,

B. W., \& Wilson, M. S. (2016). Position paper for guiding response to non-suicidal selfinjury in schools. School Psychology International, 37, $644-663$. http://dx.doi.org/10.1177/0143034316678656

Hasking, P., Rees, C. S., Martin, G., \& Quigley, J. (2015). What happens when you tell someone you self-injure? The effects of disclosing NSSI to adults and peers. BMC Public Health, 15, 1039. http://dx.doi.org/10 $.1186 / \mathrm{s} 12889-015-2383-0$

Heath, N. L., Toste, J. R., \& Beettam, E. L. (2006). “I am not well- equipped”: High school teachers perceptions of self-injury. Canadian Journal of School Psychology, 21, 73-92. http://dx.doi.org/10.1177/ 0829573506298471

Heath, N. L., Toste, J. R., Sornberger, M. J., \& Wagner, C. (2011). Teachers' perceptions of non- 
(C) American Psychological Association, 2019. This paper is not the copy of record and may not exactly replicate the authoritative document published in the APA journal. Please do not copy or cite without author's permission. The final article is available at: $: 10.1037 /$ ser0000352

suicidal self-injury in the schools. School Mental Health: A Multidisciplinary Research and Practice Journal, 3, 35- 43. http://dx.doi.org/10.1007/s12310-010-9043-4

Jarvi, S., Jackson, B., Swenson, L., \& Crawford, H. (2013). The impact of social contagion on non-suicidal self-injury: A review of the literature. Archives of Suicide Research, 17, 119. http://dx.doi.org/10.1080/ 13811118.2013.748404

Jorm, A. F., Kitchener, B. A., Sawyer, M. G., Scales, H., \& Cvetkovski, S. (2010). Mental health first aid training for high school teachers: A cluster randomized trial. BMC Psychiatry, 10, 51. http://dx.doi.org/10.1186/1471-244X-10-51

Kelada, L., Hasking, P., \& Melvin, G. A. (2017). School response to self-injury: Concerns of mental health staff and parents. School Psychol- ogy Quarterly, 32, 173-187. http://dx.doi.org/10.1037/spq0000194

Kiekens, G., Claes, L., Demyttenaere, K., Auerbach, R. P., Green, J. G., Kessler, R. C., \& Bruffaerts, R. (2016). Lifetime and 12-month nonsui- cidal self-injury and academic performance in college freshmen. Suicide and Life-Threatening Behavior, 46, 563-576.

Klonsky, E. D., May, A. M., \& Glenn, C. R. (2013). The relationship between nonsuicidal selfinjury and attempted suicide: Converging ev- idence from four samples. Journal of Abnormal Psychology, 122, 231- 237. http://dx.doi.org/10.1037/a0030278

Kutcher, S., Wei, K., McLuckie, A., \& Bullock, L. (2013). Educator mental health literacy: A 
(C) American Psychological Association, 2019. This paper is not the copy of record and may not exactly replicate the authoritative document published in the APA journal. Please do not copy or cite without author's permission. The final article is available at: $: 10.1037 /$ ser0000352

programme evaluation of the teacher training educa- tion on the mental health and high school curriculum guide. Advances in School Mental Health Promotion, 6, 83-93. http://dx.doi.org/10.1080/ 1754730X.2013.784615

Lewis, S. P., \& Heath, N. L. (2013). Nonsuicidal self-injury. Canadian Medical Association Journal, 185, 505. http://dx.doi.org/10.1503/cmaj.120969

Lewis, S. P., \& Heath, N. L. (2015). Nonsuicidal self-injury among youth. The Journal of Pediatrics, 166, $526-530$. http://dx.doi.org/10.1016/j.jpeds.2014.11.062

Lewis, S. P., Mahdy, J. C., Michal, N. J., \& Arbuthnott, A. E. (2014). Googling self-injury: The state of health information obtained through online searches for self-injury. Journal of the American Medical Association Pediatrics, 168, 443- 449. http://dx.doi.org/10.1001/jamapediatrics.2014.187

Martin, G., Richardson, A. S., Bergen, H. A., Roeger, L., \& Allison, S. (2005). Perceived academic performance, self-esteem and locus of con- trol as indicators of need for assessment of adolescent suicide risk: Implications for teachers. Journal of Adolescence, 28, 75- 87. http://dx.doi.org/10.1016/j.adolescence.2004.04.005

Muehlenkamp, J. J., Claes, L., Havertape, L., \& Plener, P. L. (2012). International prevalence of adolescent non-suicidal self-injury and de- liberate self-harm. Child and Adolescent Psychiatry and Mental Health, 6, 10. http://dx.doi.org/10.1186/1753-2000-6-10

Muehlenkamp, J. J., Walsh, B. W., \& McDade, M. (2010). Preventing non-suicidal self-injury in 
(C) American Psychological Association, 2019. This paper is not the copy of record and may not exactly replicate the authoritative document published in the APA journal. Please do not copy or cite without author's permission. The final article is available at: $: 10.1037 /$ ser0000352

adolescents: The signs of self-injury program. Journal of Youth and Adolescence, 39, 306 -314. http://dx.doi.org/10.1007/s10964-009-9450-8

Nixon, M. K., Cloutier, P., \& Jansson, S. M. (2008). Nonsuicidal self-harm in youth: A population-based survey. Canadian Medical Association Journal, 178, 306 -312. http://dx.doi.org/10.1503/cmaj.061693

Prinstein, M. J., Heilbron, N., Guerry, J. D., Franklin, J. C., Rancourt, D., Simon, V., \& Spirito, A. (2010). Peer influence and nonsuicidal self injury: Longitudinal results in community and clinically-referred ado- lescent samples. Journal of Abnormal Child Psychology, 38, 669 - 682. http://dx.doi.org/10.1007/s10802-010-9423-0

Roberts-Dobie, S., \& Donatelle, R. J. (2007). School counselors and student self-injury. The Journal of School Health, 77, 257-264. http:// dx.doi.org/10.1111/j.17461561.2007.00201.x

Rosenrot, S. A., \& Lewis, S. P. (2018). Barriers and responses to the disclosure of non-suicidal self-injury: A thematic analysis. Counselling Psychology Quarterly. Advance online publication. http://dx.doi.org/10.1080/09515070.2018.1489220

Rotolone, C., \& Martin, G. (2012). Giving up self-injury: A comparison of everyday social and personal resources in past versus current self- injurers. Archives of Suicide Research, 16, 147-158. http://dx.doi.org/ 10.1080/13811118.2012.667333

Schatten, H. T., Morris, B. W., Wren, A. L., \& Andover, M. S. (2013). Mental health issues and 
(C) American Psychological Association, 2019. This paper is not the copy of record and may not exactly replicate the authoritative document published in the APA journal. Please do not copy or cite without author's permission. The final article is available at: $: 10.1037 /$ ser0000352

nonsuicidal self-injury among youth: Implica- tions for mental health professionals in the school system. School Psychology Forum, 7, 136 -147.

Swannell, S. V., Martin, G. E., Page, A., Hasking, P., \& St John, N. J. (2014). Prevalence of nonsuicidal self-injury in nonclinical samples: Systematic review, meta-analysis and meta-regression. Suicide and Life-Threatening Behavior, 44, 273-303. http://dx.doi.org/10.1111/sltb.12070

Toste, J. R., \& Heath, N. L. (2010). School response to non-suicidal self-injury. Prevention Researcher, 1, $14-17$.

Walsh, B. W. (2012). Treating self-injury: A practical guide. New York, NY: Guilford Press.

Walsh, B., \& Muehlenkamp, J. J. (2013). Managing nonsuicidal self-injury in schools: Use of a structured protocol to manage the behavior and prevent social contagion. School Psychology Forum, 7, 161-171.

Whitlock, J., Muehlenkamp, J., Eckenrode, J., Purington, A., Baral Abrams, G., Barreira, P., \& Kress, V. (2013). Nonsuicidal self-injury as a gateway to suicide in young adults. Journal of Adolescent Health, 52, 486 - 492. http://dx.doi.org/10.1016/j.jadohealth.2012.09.010

You, J., Lin, M. P., Fu, K., \& Leung, F. (2013). The best friend and friendship group influence on adolescent nonsuicidal self-injury. Jour- nal of Abnormal Child Psychology, 41, 9931004. http://dx.doi.org/10.1007/s10802-013-9734-z 
(C) American Psychological Association, 2019. This paper is not the copy of record and may not exactly replicate the authoritative document published in the APA journal. Please do not copy or cite without author's permission. The final article is available at: :10.1037/ser0000352

\section{Tables and Figures}

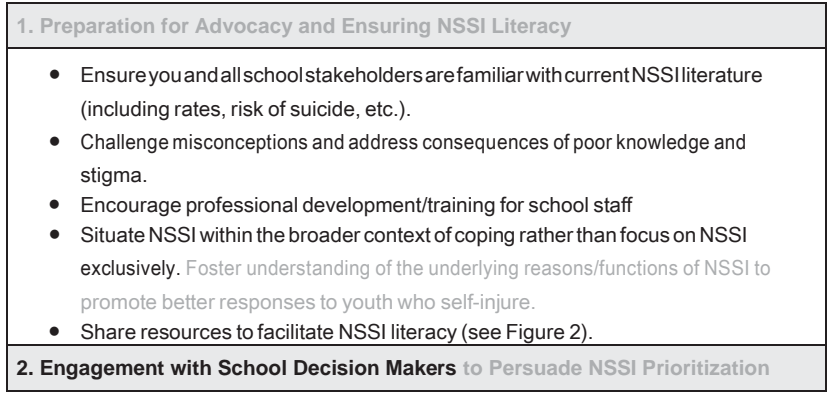


(C) American Psychological Association, 2019. This paper is not the copy of record and may not exactly replicate the authoritative document published in the APA journal. Please do not copy or cite without author's permission. The final article is available at: :10.1037/ser0000352

- Meetandengagewiththose indecision-makingrolesforschools (e.g... administrators).

- Underscore import of addressing NSSI in schools and being progressive in these aims and in the goal to enhance overall mental health and wellbeing of students.

- Share NSSI-related resources to increase knowledge (see Figure 2).

3. Develop Agreed Upon Protocol with Defined Roles

- Recommendations for NSSI school protocol: Roles \& Responsibilities:

- Identify roles and responsibilities of all staff for detecting and responding to NSSI. This should include a point person and/or team with relevant training to undertake casemanagement.

- Convey to all staff the import of referring students to the point person/team if NSSI is suspected. Confidentiality should be emphasized. From here, the first responder should be informed that a proper follow-up occurred (mindful of confidentiality limitations). Staff may experience intense feelings or reactions. Referral for the staff as needed should be available. Risk Assessment

- Only trained point-person/team to conduct risk assessment (including suicide Referral: risk). Resultant information to guide next steps (contingent on level of risk).

$\circ$ Pointperson/teaminvolvedengages in referral as needed, including, if appropriate, a parent/guardian.

- Provision of referral options for different risk profiles, and socio-economic level, as well as provision of NSSI-related resources (see Figure2). Parent/Guardian Notification:

- As needed and ideally with student involvement (and providing resources). 4. Involvement of Educational/School Boards

- Engage with education/school boards to develop a protocol for your school. - Ensure this is distinct from suicide protocols.

5. Implement Protocol/Share Resource

- Pursuant to implementing the protocol, share protocol with other schools and/or school boards.

6. Monitor Implementation

- Monitor and evaluate the implementation of the protocol; this can help determine if training needs to be updated and when.

- Initial check-ins and debriefing with staff should occur during early implementation 7. Involve New School Personnel

- As school personnel may change, ensure new personnel are trained and informed about the protocol, including their role(s). Yearly review will be helpful.

- Determine if additional training is needed if significant changes in staff.

Figure 1. Recommended steps when advocating for nonsuicidal self- injury (NSSI) school protocols.

\begin{tabular}{|l|}
\hline \multicolumn{1}{|c|}{ WEBSITES } \\
\hline Self-injury Outreach \& Support (SiOS): www.sioutreach.org \\
\hline $\begin{array}{l}\text { Provides empirically-informed current information and resources about self-injury to } \\
\text { individuals who self-injure, including coping guides and hopeful stories from those with lived } \\
\text { experience. SiOS also provides guides for families; friends; romantic partners; schools and } \\
\text { school personnel; and various health and mental health professionals. }\end{array}$ \\
\hline Shedding Light on Self-injury: www.self-injury.org.au \\
\hline $\begin{array}{l}\text { This website offers resources for health professionals, schools, and young people, as well as } \\
\text { general information for anyone wanting more information about self-injury. }\end{array}$ \\
\hline Self-injury and Recovery Research and Resources: http://www.selfinjury.bctr.cornell.edu \\
\hline $\begin{array}{l}\text { ThiswebsitebasedatCornellUniversityoffersawiderange ofinformation aboutself-injury, } \\
\text { including informationforthosewhoself-injureandthosewhocan playasupportiverole. This } \\
\text { includes parents and families, schools, and professionals. }\end{array}$ \\
\hline \multicolumn{1}{c|}{ OPEN-ACCESS ONLINE SCHOOL RESOURCES } \\
\hline ICSES infograhpics for schools: http://sioutreach.org/resources-self-injury/for-schools/ \\
\hline
\end{tabular}


(C) American Psychological Association, 2019. This paper is not the copy of record and may not exactly replicate the authoritative document published in the APA journal. Please do not copy or cite without author's permission. The final article is available at: :10.1037/ser0000352

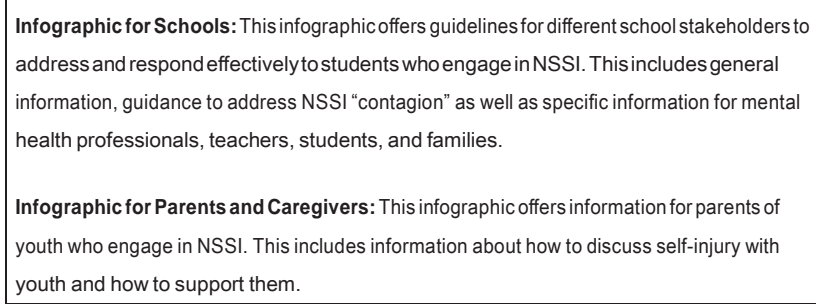

Figure 2. Recommended nonsuicidal self-injury (NSSI) resources. 